NISTIR 6163

\title{
Next-Generation Fire Suppression Technology Program (NGP)
}

Richard G. Gann

Building and Fire Research Laboratory

Gaithersburg, Maryland 20899

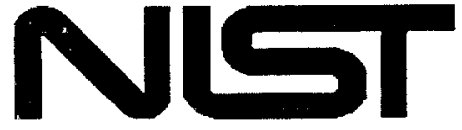

United States Department of Commerce Technology Administration

National Institute of Standards and Technology 


\section{Next-Generation Fire Suppression Technology Program (NGP)}

Richard G. Gann

May, 1998

Building and Fire Research Laboratory

National Institute of Standards and Technology

Gaithersburg, MD 20899

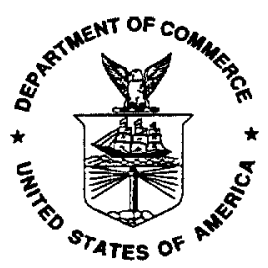

U.S. Department of Commerce

William M. Daley, Secretary Technology Administration

Gary Bachula, Acting Under Secretary for Technology

National Institute of Standards and Technology

Raymond G. Kammer, Director 


\title{
NEXT-GENERATION FIRE SUPPRESSION TECHNOLOGY PROGRAM (NGP)
}

\author{
Richard G. Gann \\ Building and Fire Research Laboratory \\ National Institute of Standards and Technology \\ Gaithersburg, MD 20899 USA
}

\begin{abstract}
The NGP, now in its second year, has as its goal the development by 2004 of alternative fire fighting technologies to halon 1301 that can be economically implemented in aircraft, ships, land combat vehicles, and critical mission support facilities. This paper describes the first projects and their early results.
\end{abstract}

\section{BACKGROUND}

In FY1997, The Department of Defense (DoD) initiated the NGP, an 8-year, \$46 million research program to develop new fire suppression technologies for the replacement of halon 1301 in weapon systems. Halon $1301\left(\mathrm{CF}_{3} \mathrm{Br}\right)$ has long been the choice for fire extinguishment in most weapon systems and mission-critical facilities. However, due to its high ozone-depletion potential, halon 1301 was banned from production as of January 1, 1994, under the Copenhagen Amendments to the Montreal Protocol on Substances that Deplete the Ozone Layer.

The NGP is a logical extension of prior DoD efforts that had identified viable, near-term halon alternatives for weapon systems. These alternatives typically require double or triple the weight and volume. While they can be readily accommodated in new system designs, they pose a significant problem to existing weapon systems because of form, fit, and function constraints. Given the current extensions of in-service lives of fielded weapon systems, this problem could ultimately require $\mathrm{DoD}$ program managers to expend large amounts of funding and time for fire suppression system redesign and reconfiguration.

The NGP goal is to develop and demonstrate, by 2004, retrofitable, economically feasible, environmentally acceptable and user-safe processes, techniques, and fluids that meet the operational requirements currently satisfied by halon 1301 systems in current aircraft, ships, land combat vehicles, and critical mission support facilities. The NGP could eliminate DoD dependence on a substance no longer in production, minimize readiness impacts of future halon 1301 use restrictions, and achieve these at greatly reduced cost.

The potential fire locations for which alternatives to halon 1301 are sought include aircraft engine nacelles, dry bays, cargo bays, and fuel tanks; ground vehicle crew compartments; and shipboard machinery spaces and storage compartments. These locations vary in size, shape and occupancy; the fuels are solids, vapors and liquids (pools and sprays); and the suppression times range from about $0.01 \mathrm{~s}$ to $100 \mathrm{~s}$. The hazards to be avoided include harm to people, thermal damage, post-fire corrosion, loss of visibility, and overpressure. Successful candidates must thus do well in: fire 
suppression efficiency and reignition quenching, ODP, GWP, atmospheric lifetime, suppressant residue level, electrical conductivity, metals non-corrosivity and polymeric materials compatibility, long-term storage stability, low toxicity of the chemical and its combustion and decomposition products, speed of dispersion, and safety. To be cost-effective, the suppressant and storage/delivery system must be light and compact, as well as compatible with the host designs of existing platforms. Information on the NGP strategy can be found at the web site: www.dtic.mil/ddre/fire_suppression/.

\section{CURRENT PROJECTS}

The NGP is now in its second year of operation. Ten projects began in FY1997, six of which are continuing into FY1998. Fifteen additional projects were initiated recently in FY1998. While the overall effort can be described in different ways, at this early stage of the NGP, it appears most informative to use the following structure. The full progress reports will soon be available at the NGP web site: www.dtic.mil/ngp/.

\section{A. DATA ON CURRENT FIRES AND SUPPRESSION SYSTEMS}

Development of Model Fires For Fire Suppression Research; Principal Investigator: Anthony Finnerty, ARL; Associate Investigators: James Tucker, AFRL and Juan Vitali, ARA, Ronald Sheinson, NRL

Objectives: To characterize the types of fires on which the Military uses halon 1301 in ground vehicles, aircraft and ships; to tabulate the spatial and operational constraints of current halon 1301 systems to serve as guidance for the appropriateness of retrofit fire suppression technologies.

Status: A report is in draft, characterizing halon 1301 fire suppression systems in representative current combat platforms and the type of fires on which these halon systems are used.

\section{B. VIABILITY OF NEW FIRE SUPPRESSION TECHNOLOGIES}

Relative Benefit Assessment of Fire Protection System Changes (new project); PI: Dennis Weiland, AFRL

Objective: To develop a methodology which will quantify a technology by its cost in order to determine if it is sufficiently superior to the state of the art to warrant further pursuit; to provide a groundwork for a future, more comprehensive model to be used by weapons program managers for determining, via life cycle costs, the most appropriate alternative to use to replace halon 1301 in their systems; to use the developed methodology to identify the aspects of fire protection technologies which offer the highest potential payoffs. This knowledge can be fed back into the NGP for immediate exploitation. 
Laser-based Instrumentation For Real-time, In-situ Measurements of Combustible Gases, Combustion By-products, And Suppressant Concentrations; PI: Kevin McNesby, ARL

Objective: To develop and demonstrate/validate new laser-based instrumentation for the measurement of concentrations of candidate suppressants, oxygen, fuels, and combustion byproducts during suppression of flames and explosions; To measure gas production and distribution during suppression of deflagrations in crew and engine compartments of a ground vehicle.

Status: A test rig has been installed in a Bradley fighting vehicle for measurement of $\mathrm{HF}$ using NIR-TDL absorption spectroscopy, FT-IR spectroscopy and using a fluoride ion electrode. In-situ, real time measurement of HF during suppression of JP-8 fuel fires showed the effectiveness of HF scavenging agents added to fluorocarbon-based suppressants. NIR-TDL was also used to measure $\mathrm{O}_{2}$ during suppression of fires in the crew compartment. Laser-induced breakdown spectroscopy is being developed for detection of flame suppressants and of some combustion products

Fast Response Species Characterization During Flame Suppression (new project); PI: George Mulholland, NIST

Objective: To develop new instrumentation for measuring agent concentration during a release with a $10 \mathrm{~ms}$ time response, fast enough to follow the fastest fires experienced in current weapons systems.

\section{SUPPRESSANT SCREENING TESTS}

Dispersed Liquid Agent Fire Suppression Screen; PI: Jiann C. Yang, NIST

Objective: To develop a bench-scale suppression screen (or multiple screens) for comparing the flame extinction performance of dispersed gases and liquids.

Status: A flow facility and modified, propane-air Tsuji-type burner have been developed for routine determination of the flame suppression effectiveness of both gaseous and aerosol suppressants. Extinction is defined as when blow-off, an abrupt transition from a stable enveloped flame to a wake flame, occurs. The performances of the burner and the flow facility have been characterized and calibrated using gaseous suppressants. The performance of several prototype droplet generators is currently being evaluated using water droplets.

Suppression System Effectiveness Screening (new project); PI: William Grosshandler, NIST

Objective: To design and construct a well-characterized bench-scale suppression screen for measuring the effectiveness of gaseous agents and dispersed fluid mists in suppressing and preventing re-ignition of a turbulent, obstructed flame burning either gaseous or condensed fuels; to evaluate the impact of transient agent delivery on flame extinguishment; to screen the effects of agents on condensed (solid and liquid) fuel surfaces. 


\section{Toxicological Assessment of Human Health Consequences Associated with Inhalation of Halon Replacement Chemicals (new project); PI: Gary Jepson, AFRL}

Objective: To provide a defensible approach and appropriate tools for decision makers, tasked with balancing performance and personnel safety issues, to evaluate the acute toxicity potential of inhaled fire suppressants.

Agent Compatibility with People, Materials and the Environment; PIs: Marc Nyden, NIST; Stephanie Skaggs, Universal Technical Services

Objective: To identify and document the best available screening methods for the toxicity, environmental impact, and materials compatibility of new suppressants and their fire degradation products; to identify those screening methods needing further development to meet the needs of the NGP.

Status: A workshop of experts in these fields was held November 14-15, 1997. The unanimous agreement was that there are no research areas, other than those already being pursued, that required new efforts in FY1999. A report on the screens to be used is being prepared.

Environmental Impact of New Chemical Agents for Fire Suppression (new project); PIs: Robert Huie, NIST, and Andrzej Miziolek, ARL

Objective: To evaluate candidate agents from new chemical families in order to establish their environmental impact and behavior during storage

\section{NEW FLAME SUPPRESSION CHEMISTRY}

Mechanisms of Ultra-high Efficiency Chemical Suppressants; PIs: Kevin McNesby, ARL and James Fleming, NRL

Objective: To determine how chemicals that are as or more efficient than halon $1301\left(\mathrm{CF}_{3} \mathrm{Br}\right)$ quench the various flames of military interest; using iron pentacarbonyl as the prototype "superagent" fire suppressant, to understand key chemical reactions or processes of combustion which are affected by "superagent" suppressants and how these reactions or processes differ from those important for fire suppression by halon 1301; to determine minimum properties for a "superagent" suppressant; to identify other candidate high-efficiency chemical fire suppression agents as candidates for replacing halon 1301.

Status: A comprehensive literature survey has been completed of flame inhibition and flame suppression data on "superagents," chemicals that are at least as effective as halon 1301. Lowpressure, opposed flow, methane/air diffusion flames, both unperturbed and with the addition of 
$\mathrm{CF}_{3} \mathrm{Br}$ and $\mathrm{Fe}(\mathrm{CO})_{5}$ were characterized. The flame character and extinction concentration for $\mathrm{Fe}(\mathrm{CO})_{s}$ added to the oxidizer side were determined. The capability to measure visible emission, infrared, and $\mathrm{OH}$ spectra were added. Changes in $\mathrm{C}_{2}$ and $\mathrm{CH}_{2}$ radicals upon addition of $\mathrm{Fe}(\mathrm{CO})_{5}$ to the oxidizer stream were measured. The size, composition, and infrared reflectance spectroscopy of particulates formed during inhibition of low pressure methane/air flames inhibited by $\mathrm{Fe}(\mathrm{CO})_{5}$ were measured.

Identification and Proof Testing of New Total Flooding Agents; PI: Robert E. Tapscott, NMERI

Objectives: To identify and develop performance data for best compounds from among the following classes: phosphorous nitrides, silanes, siloxanes, and perhaps fluorinated amines and/or ethers; determine which types of these chemicals are the best candidates for further study.

Status: This project has been completed. A detailed examination has been performed of the ODP, GWP, and toxicity estimates and the development of synthetic procedures for a range of silicon and phosphorus compounds, fluorinated amines and fluorinated ethers. A number of these appear to have potentially acceptable fire suppression, toxicity, and environmental properties.

Flame Inhibition by Phosphorus-containing Compounds; PI: Elizabeth M. Fisher, Cornell University

Objective: To identify and evaluate the flame extinction performance and toxicity of highly effective, low-ODP and low-GWP phosphorus-containing fire suppressants that could be used as total flooding agents.

Status: A novel method for approaching extinction was devised for low-vapor-pressure additives. Dimethyl methylphosphonate and trimethyl phosphate were found to be 2-4 times as effective as $\mathrm{CF}_{3} \mathrm{Br}$ as a flame suppressant in propane/air diffusion flames. A literature search shows that some PCCs likely to have low environmental impact and low toxicity.

Tropodegradable Bromocarbon Extinguishants (new project); PI: J. Douglas Mather, NMERI

Objective: To identify, synthesize and test the flame extinguishment capability of organobromine compounds with estimated acceptably low toxicity, ODP, and GWP that could be used as flooding agents.

Main Group Compounds as Extinguishants (new project); PI: J. Douglas Mather, NMERI

Objective: To determine whether there are compounds based on the chemistries of sulfur, silicon, boron, etc. that are suitable for fire suppression; and, if so, identify promising candidates for full characterization 
Super-effective Thermal Suppressants (new project); PI: William Pitts, NIST

Objective: To assess whether or not thermal fire extinguishing agents comparable in efficiency to halon 1301 are feasible, and, if so, to provide a list of the best potential candidates and their properties along with recommendations for additional testing.

\section{E. BETTER USE OF WATER}

Suppression Effectiveness of Aerosols and Particles; PI: Ronald Sheinson, NRL

Objectives: To quantify the effect of aerosol properties on the efficiency of gas-phase flame suppression and develop a list of liquids and solids manifesting desirable values of these properties.

Status: A powder delivery system was designed and integrated into a counterflow diffusion flame (CFDF) burner assembly. Extinction concentrations for propane/air flames were determined for potassium bicarbonate, sodium bicarbonate, and potassium bicarbonate, each sized from $<38 \mu \mathrm{m}$ to $>90 \mu \mathrm{m}$. Potassium (vs. sodium) and smaller particle size yielded higher efficiency. Particle sizes diminished as particles penetrated the flames. Aerosol momentum is also a key factor for suppression effectiveness, especially if the aerosol and air velocities differ.

Droplet Interactions with Hot Surfaces (new project); PI: Yudaya Sivathanu, En'Urga, Inc.

Objective: To obtain the data and understanding of interactions with burning surfaces required to engineer improved heterogeneous agent dispersion systems with enhanced fire-extinction capability.

Technical Support for the Study of Droplet Interactions with Hot Surfaces (new project); PI: Jiann Yang, NIST

Objective: To provide fluid property and possibly droplet impact data for the study of the dynamics of droplet/surface interaction and its effect on burning cessation to be conducted by other PI $s$ in the $2 b$ projects.

Electrically Charged Water Mists for Extinguishing Fires; Principal Investigator: Charles H. Berman, AeroChem Research Laboratory, Titan Corp.

Objective: Determine whether charged water droplets are drawn to a fire and are more effective at suppressing it. 
Status: The project has been completed. For exposed, 5 and $10 \mathrm{~cm}$ diameter, turbulent heptane pool fires sitting well above the floor in a ventilated chamber, in the presence of a grounding electrode, extinguishment times were significantly reduced by charging the water spray at 5 and $15 \mathrm{kV}$. The charging also induced significant spreading of the water spray.

Development of a Self Atomizing Form of Water; PI: Richard K. Lyon, EER, Inc.

Objectives: Make mist systems consisting of molecular hydrates and determine whether they "explode" downstream, increasing the effectiveness of total flooding; assess whether flashing of water can be effected by molecular hydrates and the approximate temperature range over which this is possible.

Status: The project has been completed. $\mathrm{CO}_{2}$ hydrate was been found to disperse water effectively. However, the self-atomization was ineffective at extinguishing an obstructed flame. Upon analysis of the possible causes for the failures, the potential for success was deemed low and further research along this line was not recommended.

\section{F. NEW AEROSOLS AND POWDER SUPPRESSANTS}

Powder-matrix Systems (new project); PI: Donald Burgess, NIST

Objective: To assess, and if reasonable develop, the capability for encapsulating in inorganic media, toxic but efficient fire suppression agents, enabling safe delivery to the fire, where the high temperatures will release the agent efficiently.

Dendritic Polymers as Fire Suppressants (new project); PI: Nora Beck Tan, ARL

Objective: To evaluate the potential for using metals, internally complexed in a dendritic polymer shell, as halon 1301 replacements.

\section{G. BETTER SUPPRESSANT DELIVERY}

Stabilization of Flames; PI: Vincent Belovich, AFRL

Objectives: To understand how and the extent to which flame stabilization behind bluff bodies can reduce the observed effectiveness of a suppressant and guide identification of technologies that mitigate this limit to suppression efficiency; to establish worst cases for extinguishment by gaseous, liquid, and solid suppressants and the increases in agent concentrations needed to cause flame extinguishment. 
Status: A workshop was held to define practical geometries for consideration. Determination of the most effective flame stabilization geometries is now being accomplished by: (1) Experiments. Preliminary results indicated that more stable flames were produced when the fuel was injected into the wake of a flow obstruction, producing a diffusion flame. (2) Modeling of a variety of configurations. Geometries with a cavity were generally more stable than the cases where a flame is stabilized downstream of a single bluff-body. Since both sets of results showed that the geometry of a cavity formed between two steps is the most stable, this is a likely candidate for the moredetailed testing later in the program.

Dual Agent Approach to Crew Compartment Explosion Suppression (new project); PI: Douglas Dierdorf, ARA Corp.

Objective: To determine the feasibility of a two-shot (powder, followed by water mist) system for fire suppression in a combat vehicle crew compartment.

Suppressant Flow Through Piping (new project); PI: John Chen, Lehigh University

Objective: Develop and validate a computer code capable of predicting single- and two-phase hydrodynamic behavior of fire suppressant fluids during transport through piping systems: pressure losses and flow rates for a variety of fluids; through piping systems with various combinations of fittings, over a range of pressure and composition conditions, and for transient start and stop of flows, as well as for time-varying pressure heads.

H. NEW WAYS OF GENERATING SUPPRESSANTS: No projects underway

I. IMPROVED FIRE INERTION: No projects underway

\section{FY1999 AND BEYOND}

Solicitations for proposals for Element 4D (New and More Effective Fire Suppression Technologies That are Presently Conceptual) and Element 5E (Enhanced Powder Panels) were advertised in January, 1998 and closed on March 20, 1998. Decisions on the received proposals are in progress.

The next solicitation for proposals will be advertised in December, 1998, with a likely closure similar to this year. The announcements will appear in Commerce Business Daily, on the SERDP web site (http://www.serdp.gov/ngp-federal/ngp.htm), and on the soon-to-be-open NGP web site (www.dtic.mil/ngp/) 
MANUSCRIPT REVIEW AND APPROVAL

INSTRUCTIONS: ATTACH ORIGINAL OF THIS FORM TO ONE (1) COPY OF MANUSCRIPT

AND SEND TO: WERB SECRETARY, BUILDING 820, ROOM 125

TITLE AND SUBTITLE (CITE IN FULL)

Next-Generation Fire Suppression Technology Program (NGP)

CONTRACT OR GRANT NUMBER

TYPE OF REPORT AND/OR PERIOD COVERED

AUTHORIS) (LAST NAME, FIRST INITIAL, SECOND INITIAL

PERFORMING ORGANIZATION (CHECK $(X)$ ONE BOX)

GANN, RICHARD G.

X NIST/GATTHERSBURG

NIST/BOULDER

NIST/JILA

LABORATORY AND DIVISION NAMES (FIRST NIST AUTHOR ONLY)

Building and Fire Research Laboratory, Fire Science Division (865)

SPONSORING ORGANIZATION NAME AND COMPLETE ADDRESS (STREET, CITY, STATE, ZIP)

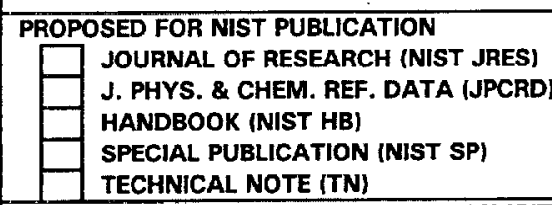

PROPOSED FOR NON-NIST PUBLICATION (CITE FULLY):

Y):

MONOGRAPH (NIST MN)

NATL. STD. REF. DATA SERIES (NIST NSRDS)

FEDERAL INFO. PROCESS. STDS. (NIST FIPS)

LIST OF PUBLICATIONS (NIST LP)

INTERAGENCYANTERNAL REPORT (NISTIR)

- U.S.

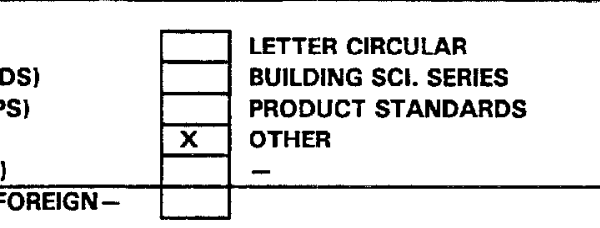

FOREIGN-

\begin{tabular}{|l|l|l|l|l|l|l|l|l|l|l|l|}
\hline PUBLISHING MEDIUM: & $\mathbf{X}$ & PAPER & & DISKETTE & & CD-ROM & & WWW & & OTHER \\
\hline
\end{tabular}

SUPPLEMENTARY NOTES

ABSTRACT (A 2000-CHARACTER OR LESS FACTUAL SUMMARY OF MOST SIGNIFICANT INFORMATION. IF DOCUMENT INCLUDES A SIGNIFICANT BIBLIOGRAPHY OR LITERATURE SURVEY, CITE IT HERE. SPELL OUT ACRONYMS ON FIRST REFERENCE.) (CONTINUE ON SEPARATE PAGE, IF NECESSARY.)

The NGP, now in its second year, has as its goal the development by 2004 of alternative fire fighting technologies to halon 1301 that can be economically implemented in aircraft, ships, land combat vehicles, and critical mission support facilities. This paper describes the first projects and their early results.

KEY WORDS (MAXIMUM OF 9; 28 CHARACTERS AND SPACES EACH; SEPARATE WITH SEMICOLONS; ALPHABETIC ORDER; CAPITALIZE ONLY PROPER NAMES) fire; fire research; fire suppression; halon

\section{AVAILABILITY:}

$\bar{X}$ UNLIMITED $\quad \square$ FOR OFFICIAL DISTRIBUTION - DO NOT RELEASE TO NTIS ORDER FROM SUPERINTENDENT OF DOCUMENTS, U.S. GPO, WASHINGTON, DC 20402

$\mathrm{X}$ ORDER FROM NTIS, SPRINGFIELD, VA 22161
NOTE TO AUTHOR(S); IF YOU DO NOT WISH THIS MANUSCRIPT ANNOUNCED BEFORE PUBLICATION, PLEASE CHECK HERE. 